\title{
Limitation by iron and manganese of phytoplankton communities in the Drake Passage.
}

\section{Jenna Balaguer ${ }^{1 *}$, Florian Koch², Christel Hassler ${ }^{4,5}$, Scarlett Trimborn ${ }^{1,3}$}

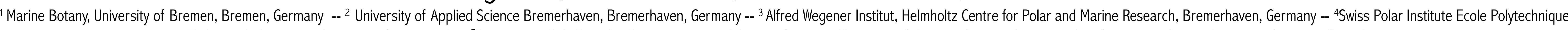
Fédérale de Lausanne, Lausanne, Switzerland -- ${ }^{5}$ Department F-A. Forel for Environmental and Aquatic Sciences, University of Geneva, Geneva, Switzerland -- *corresponding author: jenna.balaguer@awi.de

\section{$(1)$ Context of study}

- The Southern Ocean is a High Nutrient Low Chlorophyll (HNLC) region $\rightarrow$ Trace metals and especially Iron (Fe) availability are the key control for community composition and biomass

(Martin et al, 1990 ; Boyd et al., 2007 ; Sunda, 2012)

- Co-limitation of Fe with manganese (Mn) in the Drake Passage was suggested early in 1990 (Martin et al., 1990)

- Total dissolved Mn concentrations were found to be very low :

- North Pacific (Coale, 1991)

- Southern Ocean : Drake Passage, Scotia and Weddell Sea (Martin et al,, 1990 ; Buma et al, 1991 ; Middag et al., 2011; Middag et al,, 2013)

- Significant stimulation of the photosynthetic activity and biomass buildup after ash additions (including $\mathrm{Mn}$ ) of phytoplankton assemblages across the Drake Passage were reported (Browning et al, 2014)

- Only supply of Fe and Mn together led to optimal growth, photochemical efficiency and carbon production of the Antarctic diatom Chaetoceros debilis (Pausch et al, 2019)

Can Mn act as a limiting factor with Fe ?

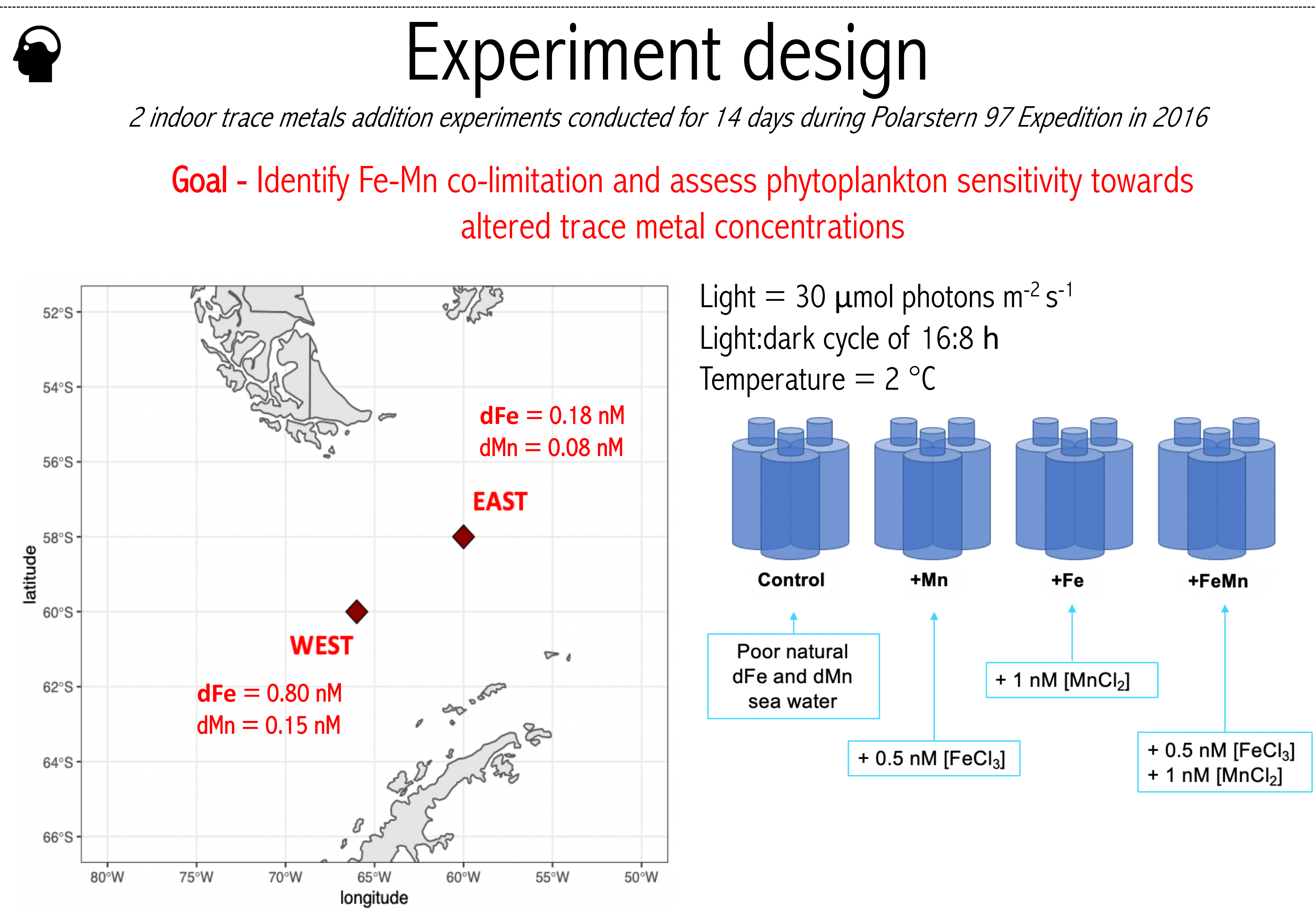

As expected for HNLC region - $>$ High macronutrients concentration $[\mathrm{N}]>23 \mu \mathrm{mol} . \mathrm{L}^{-1} / /[\mathrm{P}]>1,5 \mu \mathrm{mol} . \mathrm{L}^{-1} / /[\mathrm{Si}]>16 \mu \mathrm{mol} . \mathrm{L}^{-1}$

III

\section{Results}

\section{Station East}
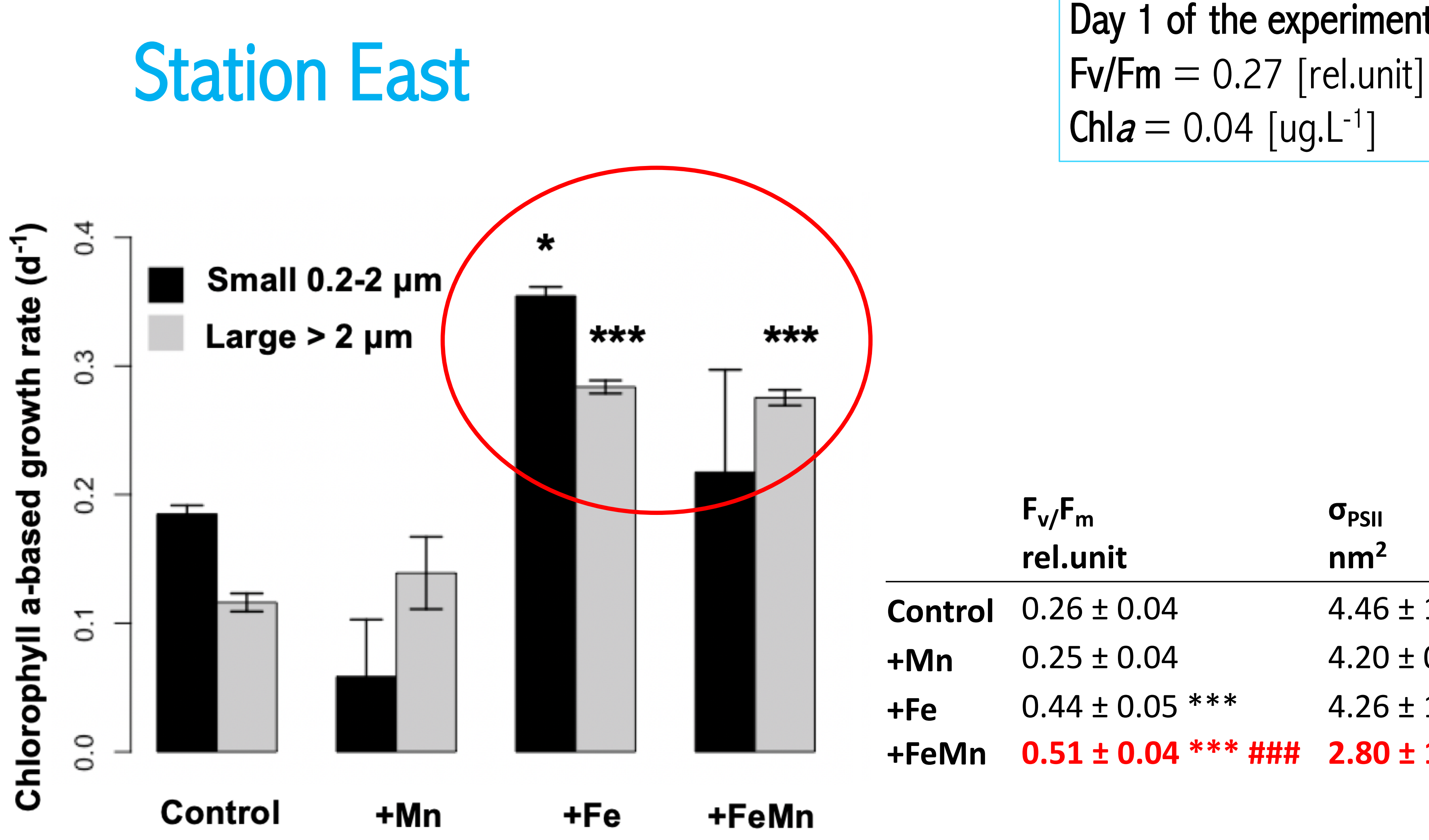

Chla $=0.04\left[\mathrm{ug} \cdot \mathrm{L}^{-1}\right]$
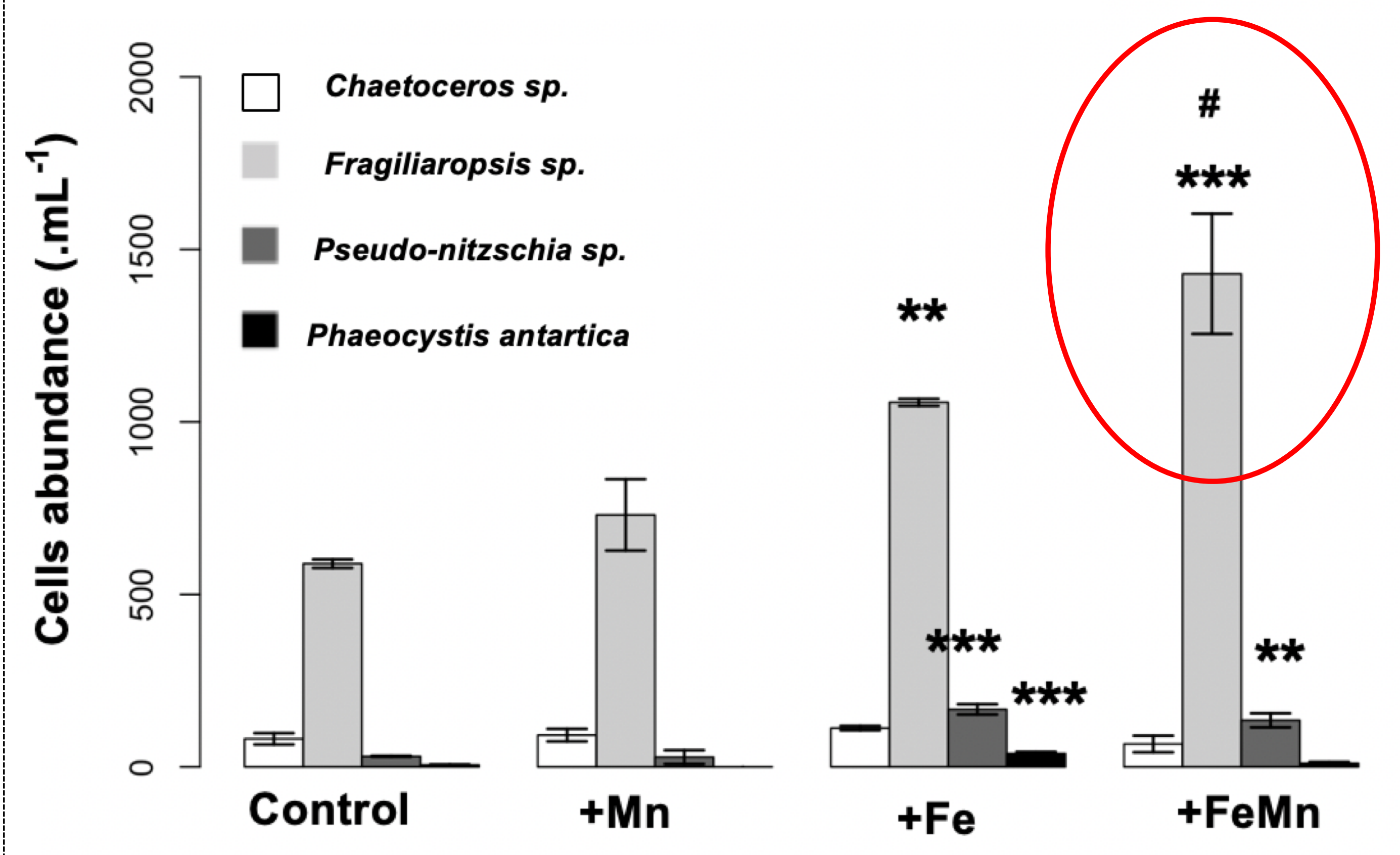
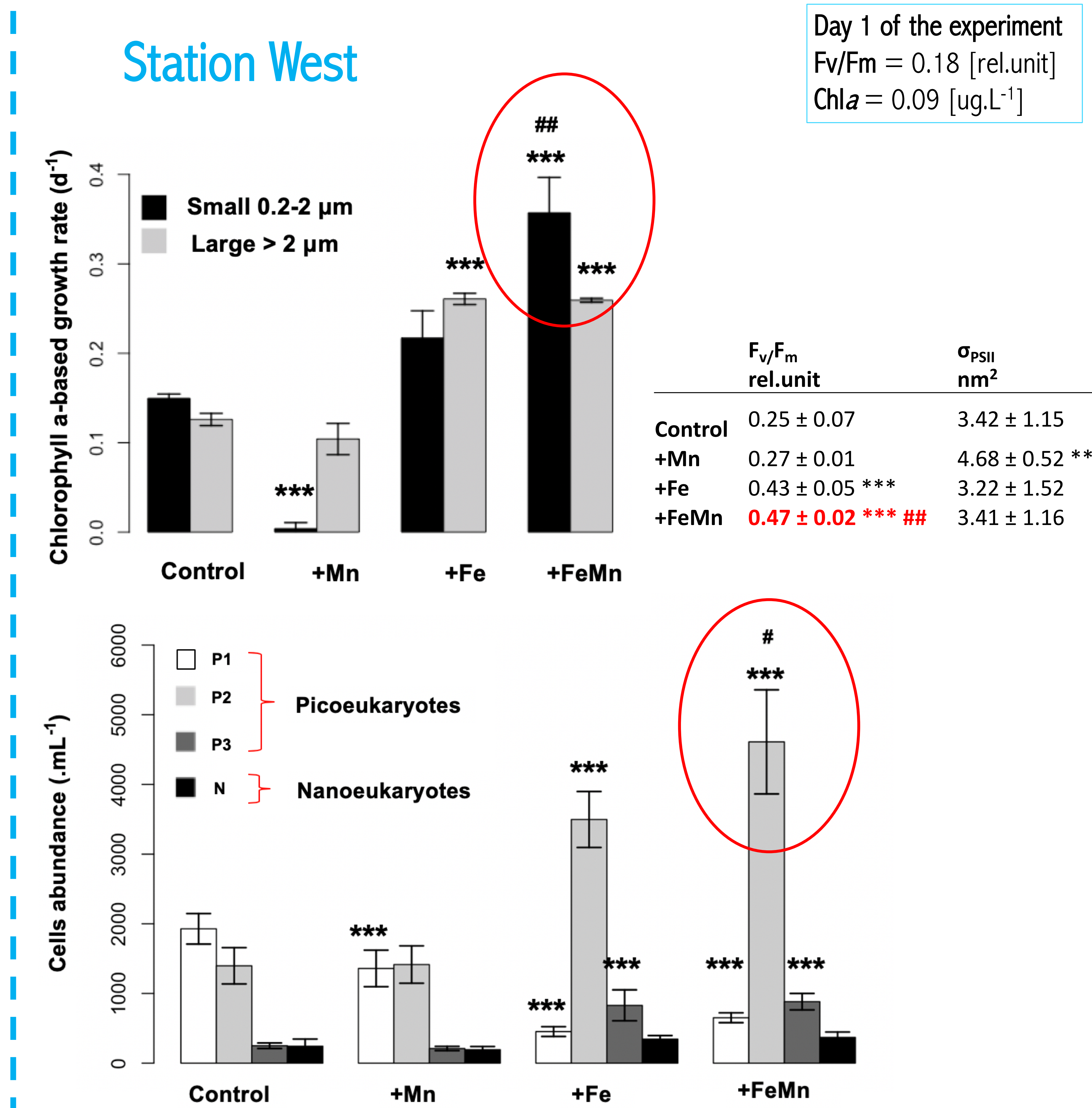

*Values represent the mean $\pm S D(n=3)$. Statistical differences (ANOVA) for each parameter relative to the Control ${ }^{*}$ ) and between $+\mathrm{Fe}$ and $+\mathrm{FeMn}$ treatment (\#) are denoted by *\# $p<0.01$, $^{* *} \# \#<0.001$ and ${ }^{* * *} \# \# p<0.0001$.

\section{Ecological implications}

- Observe changes are not only explained by $\mathrm{Fe} \rightarrow$ Addition of both trace elements together promoted a shift in the species composition

- Maximum photosynthetic efficiency reached only when Fe and Mn were added together

- On the basis of the photophysiological signature of $F_{v /} F_{m}$ and $\sigma_{P S I I} \rightarrow$ Fe limitation cannot be differentiated from a Fe-Mn co-limitation

- To go further $\rightarrow$ Species identified in field will be tested under altered trace metal concentrations for a better understanding of their requirements



